\title{
Endovascular management of symptomatic Deep Vein Thrombosis (DVT) with Combined Approach
}

\author{
Vito Gallicchio $^{1}$, Danilo Barbarisi ${ }^{1}$, Rosaria SCIARRILLO ${ }^{2}$, and Loris Flora ${ }^{1}$ \\ ${ }^{1}$ Hospital of National Importance San Giuseppe Moscati \\ ${ }^{2}$ University of Sannio Department of Sciences and Technologies
}

June 25, 2021

\begin{abstract}
The primary goal of this treatment is the restoration of venous outflow and can be achieved by combined endovascular techniques. We report a case of 38 years-old female, with leg pain and edema, skin changes, venous claudication and dyspnea for polmunary embolism.
\end{abstract}

\section{Hosted file}

Manuscript.docx available at https://authorea.com/users/421983/articles/527805-endovascularmanagement-of-symptomatic-deep-vein-thrombosis-dvt-with-combined-approach 


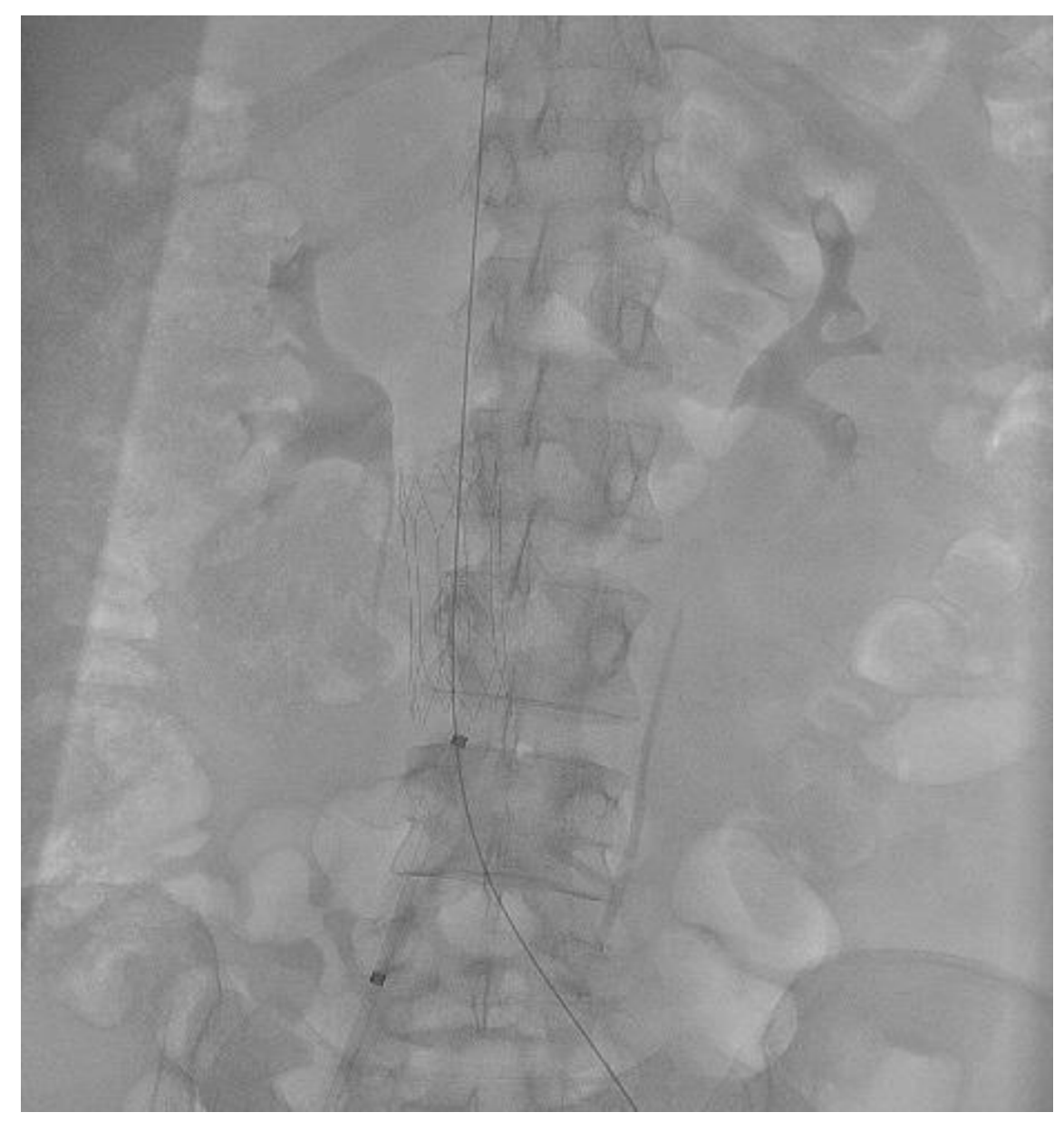




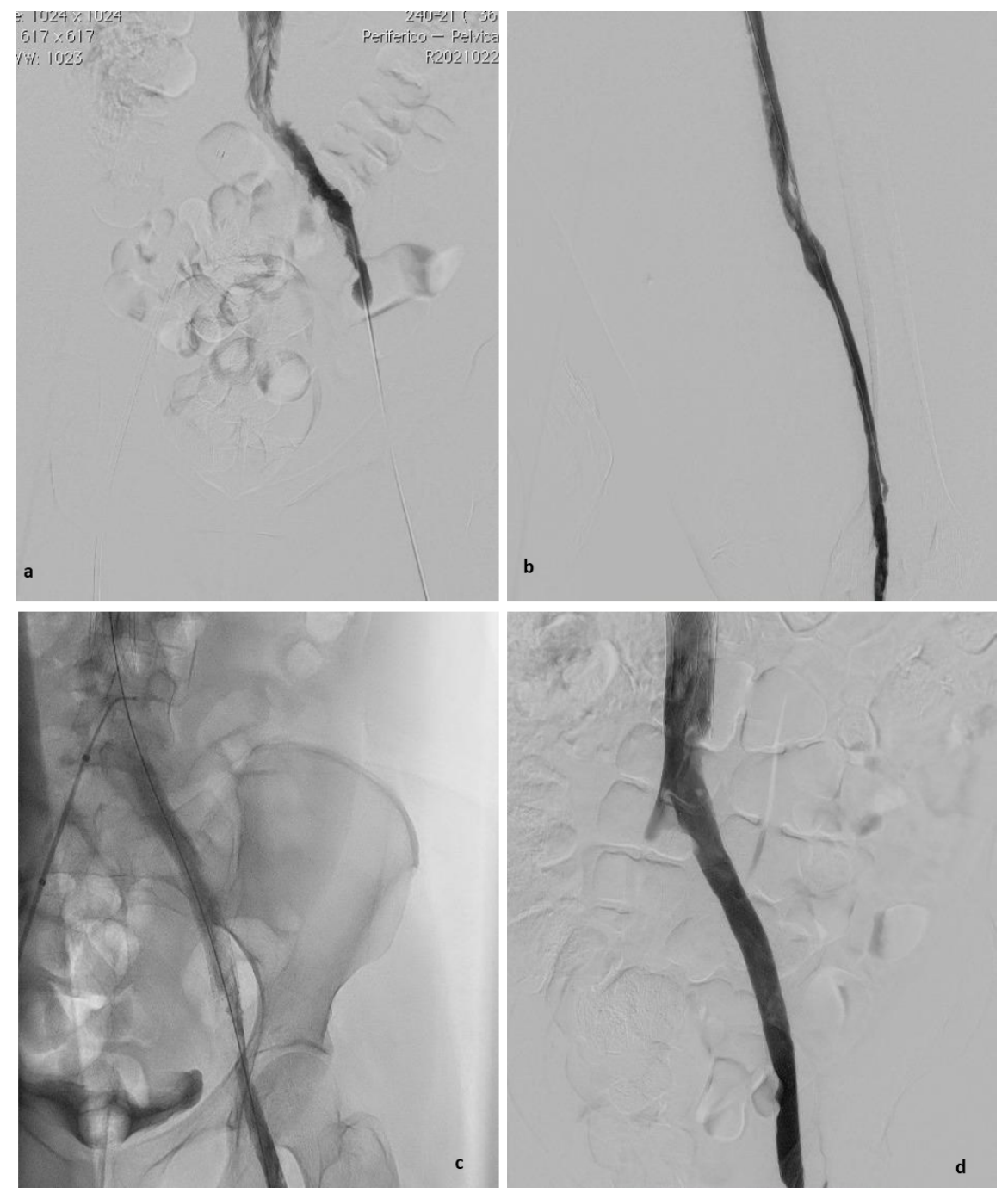

